\title{
Demographics, Redistribution, and Optimal Inflation
}

\author{
James Bullard, Carlos Garriga, and Christopher J. Waller
}

\begin{abstract}
The authors study the interaction among population demographics, the desire for intergenerational redistribution of resources in the economy, and the optimal inflation rate in a deterministic life cycle economy with capital. Young cohorts initially have no assets and wages are the main source of income; these cohorts prefer relatively low real interest rates, relatively high wages, and relatively high rates of inflation. Older cohorts work less and prefer higher rates of return from their savings, relatively low wages, and relatively low inflation. In the absence of intergenerational redistribution through lump-sum taxes and transfers, the constrained efficient competitive equilibrium requires optimal distortions on relative prices. The authors' model allows the social planner to use inflation/deflation to try to achieve the optimal distortions. In the model economy, changes in the population structure are interpreted as the ability of a particular cohort to influence the redistributive policy. When older cohorts have more influence on the redistributive policy, the economy has a relatively low steady-state level of capital and a relatively low steady-state rate of inflation. The opposite happens when young cohorts have more control of policy. These results suggest that aging population structures, such as those in Japan, may contribute to observed low rates of inflation or even deflation. (JEL E4, E5, D7)
\end{abstract}

Federal Reserve Bank of St. Louis Review, November/December 2012, 94(6), pp. 419-39.

\section{OVERVIEW}

Can observed low inflation outcomes be related to demographic factors such as an aging population? A calculation that we label as "back of the envelope" (BOTE) based on some basic economic theory might suggest that the answer is no. Suppose we think of the net real interest rate $r$ in a model with capital. We might guess that in steady state $r=\delta+n$, where $\delta$ is the net depreciation rate and $n$ is the net population growth rate. Suppose we also assume that (i) money and capital pay either the same real rate of return or closely related real rates of return $\underline{1}$ and (ii) the real return on money is the negative of the net inflation rate $\pi$. Now suppose the rate of pop-

\footnotetext{
James Bullard is president and CEO of the Federal Reserve Bank of St. Louis. Carlos Garriga is a research officer and Christopher J. Waller is senior vice president and director of research at the Federal Reserve Bank of St. Louis. This paper was presented at the conference"Demographic Changes and Macroeconomic Performance," sponsored by the Bank of Japan and the Institute for Monetary and Economic Studies, May 30-31, 2012. The authors appreciate the useful comments received from the conference participants, particularly the discussants, Hiroshi Fujiki and Philipp Hartmann.

(c) 2012, The Federal Reserve Bank of St. Louis. The views expressed in this article are those of the author(s) and do not necessarily reflect the views of the Federal Reserve System, the Board of Governors, or the regional Federal Reserve Banks. Articles may be reprinted, reproduced, published, distributed, displayed, and transmitted in their entirety if copyright notice, author name(s), and full citation are included. Abstracts, synopses, and other derivative works may be made only with prior written permission of the Federal Reserve Bank of St. Louis.
} 


\section{Bullard, Garriga, Waller}

ulation growth increases to $n^{\prime}$, creating a new steady state with a more youthful population. By itself, this must mean that the real return to capital increases to $r^{\prime}$ and that the inflation rate decreases to $\pi^{\prime}$. This fact would seem to suggest that, all else equal, countries with relatively young populations would have relatively low inflation rates and, conversely, countries with relatively old populations would have relatively high inflation rates.

However, the BOTE calculation does not seem to square with some of the facts. Figures 1 and 2 show two time series for two countries, the United States and Japan, respectively, for 1960 to 2010. A moving average (MA) of the consumer price index (CPI) inflation rate is plotted on the left scale. A measure of the youthfulness of the population-the percentage of the population 15 to 40 years of age-is plotted on the right scale. In each case, roughly speaking, economies with a higher share of a younger population are associated with higher inflation, whereas economies with a higher share of an older population are associated with lower inflation. $\stackrel{2}{\text { This }}$ evidence, while far from definitive, is at least suggestive and does run counter to the BOTE standard theory calculation.

In this article, we provide one reconciliation of the BOTE calculation with the suggestion that aging populations are associated with lower levels of inflation (see Figures 1 and 2). The theory we study has all the elements of the BOTE calculation but also considers the desire for redistribution of resources within society. We model this desire as a social planner's problem in which the planner has access to only inflation or deflation as tools to achieve redistribution. We show that the solution to the social planner's problem associates relatively older populations with relatively low inflation.

\section{Redistributional Tension}

In canonical macroeconomic models, the representative agent assumption is used to capture the average behavior of key variables, including inflation. When the representative household approach is used, policy implicitly ignores the redistributive effects of fiscal and monetary interventions. While it is possible to incorporate various forms of heterogeneity into canonical models, attempting to understand redistribution policies for demographic reasons forces us to abandon the representative agent framework and move to a general equilibrium life cycle framework.

Accordingly, in this article we use an overlapping-generations model with capital to study the redistributional tensions associated with monetary and fiscal policy. As in Bullard and Waller (2004), inflation dictates the real rate of return on money and thus the portfolio choices of each generation. By means of a standard Tobin effect, higher inflation can induce a substitution from money to capital. But why does this create a tension across generations? The tension can be understood by considering the decisionmaking of a given individual at time $t$. A high wage rate at time $t$, which we can represent as $f_{l}\left(k_{t}\right)$, increases the lifetime income of the young cohort. Inflation reduces the rate of return on money balances and individuals shift portfolio decisions toward capital. The increasing capital accumulation increases wages of young workers but reduces the rate of return on capital, $f_{k}\left(k_{t+1}\right)$, for the older cohort of savers. Consequently, workers like inflation when they are young but dislike it when they are old. Thus, if a single generation could choose the inflation rate at each point in their lives, they would choose relatively high inflation when they were young and relatively low inflation (or deflation) when old. Clearly, the generations existing side by side with this one generation would not appreciate such a policy 


\section{Figure 1}

Inflation and Demographics: United States (1960-2010)

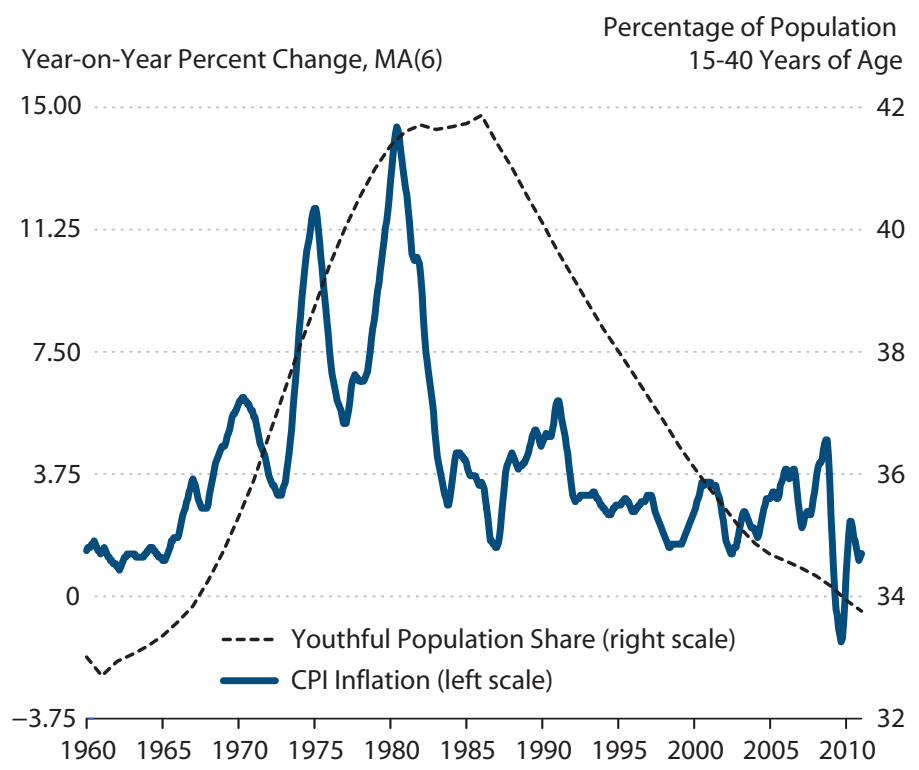

Figure 2

Inflation and Demographics: Japan (1960-2010)

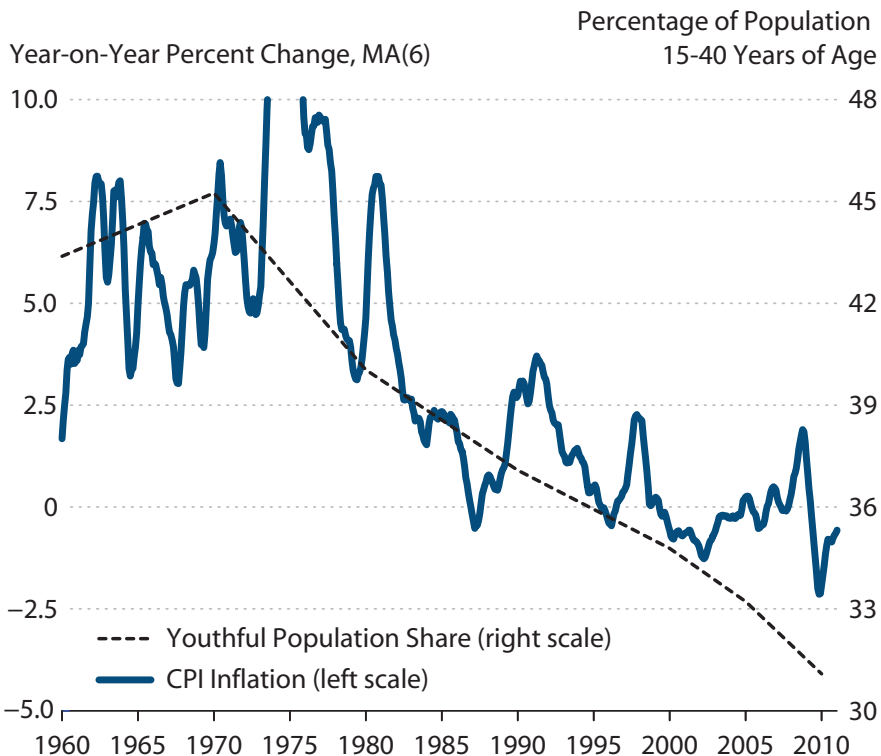




\section{Bullard, Garriga, Waller}

and would oppose it. Consequently, how agents resolve this conflict between generations is important for understanding policy choices and the institutional design of the central bank.

Bullard and Waller (2004) consider three institutional arrangements for resolving this conflict; among them is a policy committee that allows older and younger cohorts to solve a Nash bargaining problem. $\frac{3}{-}$ Their main finding is that the behavior of inflation hinges critically on key details of the institutional design.

The objective of this article is to understand the determination of central bank objectives when population aging shifts the social preferences for redistribution and its implications for inflation. Our starting point builds on Bullard and Waller (2004) but, unfortunately, it is difficult to follow their approach since it is not possible to specify the entire spectrum of institutional arrangements that could be implemented. We take a different approach here. Rather than specifying particular political decisionmaking rules, we use a direct mechanism to decide the allocations. This means we solve a social planner's problem in which the weights assigned to each generation are population weights. Thus, a baby boom corresponds to assigning more weight to the young of a particular generation relative to past and future generations. This mechanism can replicate any steady-state allocation arising from a political economy model with population growth or decline.

An optimal level of capital exists for every level of social redistribution. When the young have more influence in the planner's optimization problem, wages are high and the return from capital is low; and when the old have more influence in the planner's optimization problem, wages are low and the return from capital is high. A critical feature of the planning problem we study is whether the planner can redistribute resources by means of lump-sum taxes or transfers. In the absence of lump-sum redistribution, we show that the planner might wish to use inflation or deflation to change the relative price of capital to induce young households to hold the right amount of capital. In general, the constrained redistributive solution is not fully efficient. That is, the implied level of savings is either too low or too high compared with the unconstrained efficient solution. In this sense, inflation or deflation will turn out to be an imperfect substitute for a full system of lump-sum taxes and transfers.

We emphasize that, in contrast with Bullard and Waller (2004), the unconstrained socially efficient level of savings is always dynamically efficient. This is because in the unconstrained case the social planner has access to a full system of lump-sum taxes and transfers. However, the constraints on redistribution - when the planner has access to only inflation/deflation as redistribution tools-behave as binding participation constraints that cause the efficient level of capital to deviate from the socially efficient one. These deviations are due to the relative importance of each group and the underlying distribution of resources. $\underline{4}$

The mechanism in this article follows the work of Garriga and Sánchez-Losada (2009), who consider the implementation of constrained efficient solutions in economies with warm-glow or joy-of-giving preferences. The rationale for intergenerational redistribution is always present in a life cycle model that abstracts from lump-sum taxes and transfers. Garriga (2001) shows that, depending on the relative importance of present versus future generations, it is optimal to tax/ subsidize capital. Dávila (2012) uses a similar approach in a steady-state analysis to show that capital taxation can still be optimal even in the absence of government expenditure. This mech- 
anism is usually absent in economies with dynastic agents. Dávila et al. (forthcoming) also use a similar setup in an economy with incomplete markets and uninsurable income risk.

\section{ECONOMY}

\section{Environment}

Consider a standard two-period overlapping-generations growth model with capital. Time is discrete and double infinity $t=\ldots,-2,-1,0,1,2, \ldots$ In each period a number of identical households are born, and the population grows at an exogenous rate $N_{t}=(1+n) N_{t-1}$, where $N_{0}=1$. Each cohort lives for two periods and has perfect foresight. Young individuals are endowed with one unit of time that can be devoted to market work. Bundles of consumption goods today, $c_{1, t}$, and tomorrow, $c_{2, t+1}$, are compared using a standard utility function $U\left(c_{1, t}, c_{2, t+1}\right)=u\left(c_{1, t}\right)+$ $\beta u\left(c_{2, t+1}\right)$, where the utility function satisfies standard properties, and the term $\beta$ represents intertemporal discounting. There is an initial old cohort that consumes at $t=0$.

This economy produces consumption and investment goods with a standard neoclassical technology $F\left(K_{t}, N_{t}\right)$ that uses capital and labor as inputs. The production function has constant returns to scale and satisfies standard properties. Capital depreciates at the rate $\delta$. Output per worker can be written as $f\left(k_{t}\right)$, where $k_{t}=K_{t} / N_{t}$. The economy aggregate resource constraint is given by

$$
N_{t} c_{1, t}+N_{t-1} c_{1, t-1}+K_{t+1}=F\left(K_{t}, N_{t}\right)+(1-\delta) K_{t}
$$

or, in per capita terms,

$$
c_{1, t}+\frac{1}{1+n} c_{1, t-1}+(1+n) k_{t+1}=f\left(k_{t}\right)+(1-\delta) k_{t} .
$$

\section{The Efficient Allocation of Resources}

Consider the allocation of resources determined by a social planner. The objective function weights current and future generations according to

$$
V=\beta \lambda_{-1} u\left(c_{2,0}\right)+\sum_{t=0}^{\infty} \lambda_{t}\left[u\left(c_{1, t}\right)+\beta u\left(c_{2, t+1}\right)\right] .
$$

The term $\lambda_{t}$ can be interpreted as the social discount rate and represents the relative weight placed between present and future cohorts. Note that it is possible for $\lambda_{t}>1$ for some arbitrary generation $t$, but for exposition it is convenient to assume that discounting is geometric-that is, $\lambda_{t}=\lambda \leq 1$. The socially efficient allocation of resources is then the solution to a standard optimization problem:

$$
V\left(k_{0}\right)=\max \sum_{t=0}^{\infty} \lambda^{t}\left[u\left(c_{1, t}\right)+\beta \lambda^{-1} u\left(c_{2, t}\right)\right]
$$

subject to 


$$
c_{1, t}+\frac{c_{2, t}}{1+n}+(1+n) k_{t+1}=f\left(k_{t}\right)+(1-\delta) k_{t} .
$$

The objective function has been rewritten to illustrate the redistributive trade-offs between existing old cohorts and the new young cohort. A higher value of $\lambda$ assigns more weight to the newborn and future generations and less to the current individuals. The first-order conditions of the optimization program imply

$$
\lambda u^{\prime}\left(c_{1, t}\right)=\beta(1+n) u^{\prime}\left(c_{2, t}\right)
$$

and

$$
(1+n) u^{\prime}\left(c_{1, t}\right)=\lambda u^{\prime}\left(c_{1, t+1}\right)\left[1-\delta+f^{\prime}\left(k_{t+1}\right)\right]
$$

Both conditions are standard. Equation (6) equates the marginal rate of substitution of the young and the old at a given point in time. When $\lambda=\beta$, both individuals receive the same amount of per capita consumption. When the weight on the young cohort is larger, $c_{1, t}>c_{2, t}$. Equation (7) is the standard Euler equation but compares the marginal rate of substitution between a newborn in period $t$ and $t+1$ with the marginal rate of transformation. Combining both expressions, the model implies the standard Euler equation from the two-period overlapping-generations model as follows:

$$
u^{\prime}\left(c_{1, t}\right)=\beta u^{\prime}\left(c_{2, t+1}\right)\left[1-\delta+f^{\prime}\left(k_{t+1}\right)\right] .
$$

In steady state, the allocation of resources perfectly separates the production process (determination of the capital stock and employment) since the steady-state stock of capital $k^{s}$ is determined solely from equation (7),

$$
f^{\prime}\left(k^{s}\right)=(1+n) \lambda^{-1}+\delta-1
$$

while steady-state consumption $c_{1}^{s}$ and $c_{2}^{s}$ solve

$$
\begin{gathered}
\lambda u^{\prime}\left(c_{1}^{s}\right)=\beta(1+n) u^{\prime}\left(c_{2}^{s}\right) \\
c_{1}^{s}+\frac{c_{2}^{s}}{1+n}+(\delta+n) k^{s}=f\left(k^{s}\right) .
\end{gathered}
$$

Since $\lambda>1$, the economy always satisfies the condition for dynamic efficiency. Note that for the extreme case of $\lambda=1$, the economy satisfies the golden rule $f^{\prime}\left(k^{*}\right)=n+\delta$. Many analyses of this model ignore the role of social discounting, implicitly setting $\lambda=1$, and maximize the savings rate subject to the steady-state resource constraint. However, this particular case of the Pareto frontier is not useful for the study of intergenerational redistribution when the relative importance of one group increases.

If the analysis is restrained to only steady-state allocations, then equations (9) through (11) yield a unique solution for any value of $\lambda$. It is clear from equation (9) that for $\lambda>1, k^{s}>k^{*}$ and the economy has more capital than prescribed by the golden rule. This is the case studied by 
Bullard and Waller (2004), who looked at only political economy allocations rather than a planner allocation. In this sense, any political economy allocation occurring in the steady state of their model can be replicated by an appropriate choice of $\lambda$ confronting a social planner. However, since we want to study the dynamic behavior of inflation following a baby boom and bust, we cannot constrain our analysis to steady states. This forces us to study allocations for which $\lambda \leq 1$.

\section{Implementation of the Efficient Problem: Lump-Sum Transfers}

Markets can achieve the same allocation as the social planner. However, doing so requires a transfer of resources across cohorts using lump-sum taxation. The optimization problem of the representative newborn is given by

$$
\max u\left(c_{1, t}\right)+\beta u\left(c_{2, t+1}\right)
$$

subject to

$$
c_{1, t}+s_{t}=w_{t} l_{t}+T_{1, t} \text {, }
$$

and

$$
c_{2, t+1}=\left(1-\delta+r_{t+1}\right) s_{t}+T_{2, t+1} \text {. }
$$

The term $T_{i, t}$ represents intergenerational transfers across cohorts at time $t$. The term $r_{t}$ is the market interest rate earned from capital, and $w_{t} l_{t}$ represents labor income. The optimality conditions imply

$$
u^{\prime}\left(w_{t} l_{t}-s_{t}+T_{1, t}\right)=\beta u^{\prime}\left[\left(1-\delta+r_{t+1}\right) s_{t}+T_{2, t+1}\right]\left(1+r_{t+1}\right)
$$

The optimal interest rate determined by the intergenerational discount rate can be implemented by shifting resources across cohorts at a given period $t$; this ensures that the young cohort saves the right amount, implementing the fully efficient solution. The market clearing condition for capital implies $(1+n) k_{t+1}=s_{t}$. The government budget constraint implies

$$
T_{1, t}+\frac{T_{2, t}}{1+n}=0 .
$$

This economy is not particularly useful because neither fiscal nor monetary policy is used to implement the efficient solution. This is no longer true in the absence of redistributional policy. In this case, the direct mechanism needs to respect the distributional restrictions implied by the market. However, a constrained planner can internalize the impact of the decisions on factor prices. This solution should be superior to the one in which the direct mechanism does not consider the effect of aggregates on factor prices. The constrained efficient solution implies a wedge in market decisions (for instance, inflation or capital taxation). The optimal wedge (positive or negative) is determined by the social desirability of redistributing resources across cohorts. 


\section{Constrained Efficient Allocations: Ramsey}

In the efficient allocation, the social planner has access to lump-sum taxes and transfers. Since lump-sum taxes and transfers are rarely used in practice, we follow the traditional Ramsey approach of public finance and assume that the social planner (i) does not have access to lumpsum taxes and transfers and (ii) faces the same market prices as agents. These assumptions imply that the only way to increase consumption for a given cohort is to manipulate the incentives to save and the implied relative prices. By taking into account the effects on relative prices, the planner does not need to manipulate the allocations that much. Consider

$$
V\left(k_{0}\right)=\max \sum_{t=0}^{\infty} \lambda^{t}\left[u\left(c_{1, t}\right)+\beta \lambda^{-1} u\left(c_{2, t}\right)\right]
$$

subject to

$$
c_{1, t}=f_{l}\left(\frac{s_{t-1}}{1+n}\right) l-s_{t}
$$

and

$$
c_{2, t}=\left[1-\delta+f_{k}\left(\frac{s_{t-1}}{1+n}\right)\right] s_{t-1},
$$

where $(1+n) k_{t+1}=s_{t}$. This optimization problem is equivalent to (i) the Ramsey problems described in Garriga (2001) when the government expenditure is set equal to zero or (ii) the steady-state analysis when the planner faces no intergenerational conflict, $\lambda=1$, as in Dávila (2012).

Let $\gamma_{1, t}$ and $\gamma_{2, t}$ represent the Lagrange multipliers of the distributional constraints (17) and (18), respectively. It is important to stress that each resource constraint effectively provides an entitlement for each individual, and thus $\gamma_{1, t}$ and $\gamma_{2, t}$ are endogenous weights affecting the distribution of resources. The first-order conditions of this problem for every period $t$ yield

$$
\frac{u^{\prime}\left(c_{1, t}\right)}{u^{\prime}\left(c_{2, t}\right)}=\frac{\beta(1+n)}{\lambda} \frac{\gamma_{1, t}}{\gamma_{2, t}}
$$

The endogenous weights are the same, $\gamma_{1, t}=\gamma_{2, t}$, only if the planner does not have redistributional conflicts. When a particular cohort controls more resources, its endogenous weight is lower, thereby making it easier to transfer resources from that cohort to the other. In short, intergenerational redistribution trades off the relative importance of each cohort, $\lambda$, with the cohort's ownership of resources, $\gamma$.

The intergenerational decision on savings (capital) is more complicated:

$$
\gamma_{1, t}=\gamma_{1, t+1} f_{l, k}\left(\frac{s_{t-1}}{1+n}\right) \frac{l}{1+n}+\gamma_{2, t+1}\left[1-\delta+f_{k}\left(\frac{s_{t-1}}{1+n}\right)+f_{k, k}\left(\frac{s_{t-1}}{1+n}\right) \frac{s_{t}}{1+n}\right] .
$$

An increase in savings reduces consumption of the current generation, $c_{1, t}$. The additional savings (i) increases future consumption of the generation that saves the resources by the marginal 
product of capital, (ii) increases the wages of future newborn cohorts at $t+1$, and (iii) reduces the future rate of return of all savings. Replacing the multipliers implies

$$
\begin{gathered}
u^{\prime}\left(c_{1, t}\right)=\lambda u^{\prime}\left(c_{1, t+1}\right) f_{l, k}\left(\frac{s_{t-1}}{1+n}\right) \frac{l}{1+n} \\
+\beta u^{\prime}\left(c_{2, t+1}\right)\left[1-\delta+f_{k}\left(\frac{s_{t-1}}{1+n}\right)+f_{k, k}\left(\frac{s_{t-1}}{1+n}\right) \frac{s_{t}}{1+n}\right] .
\end{gathered}
$$

As $\lambda$ increases, the relative importance of the young cohort increases, the effect of saving on future wages is more important, and the economy accumulates more capital. In the absence of intergenerational redistribution, the only way to induce additional savings is to subsidize capital. This expression can be rewritten in wedge form as

$$
\frac{u^{\prime}\left(c_{1, t}\right)}{\beta u^{\prime}\left(c_{2, t+1}\right)}=\frac{\left[1-\delta+f_{k}\left(\frac{s_{t-1}}{1+n}\right)+f_{k, k}\left(\frac{s_{t-1}}{1+n}\right) \frac{s_{t}}{1+n}\right]}{1+\lambda \frac{u^{\prime}\left(c_{1, t+1}\right)}{u^{\prime}\left(c_{1, t}\right)} f_{k, k}\left(\frac{s_{t-1}}{1+n}\right) \frac{l}{1+n}},
$$

where $f_{k, k} k=-f_{l, k} l$. The constrained efficient solution is fully efficient only when $f_{k, k}=0$. Otherwise, the efficient solution implies an optimal wedge (positive or negative) in savings decisions. The magnitude of the wedge depends on the relative influence of each generation in the planner's objective function. Let

$$
\varphi^{k}=f_{k, k}(k) \frac{k}{f_{k}(k)}<1
$$

be the elasticity of marginal product to changes in the capital stock. If the production function is linear or has a constant marginal product, the social planner cannot manipulate prices. The other wedge is determined by

$$
\varphi_{t+1}^{\lambda}=\lambda \frac{u^{\prime}\left(c_{1, t+1}\right)}{u^{\prime}\left(c_{1, t}\right)} f_{k, k}\left(\frac{s_{t-1}}{1+n}\right) \frac{l}{1+n}<1 .
$$

Replacing the definition of the wedges in the optimality condition implies

$$
\frac{u^{\prime}\left(c_{1, t}\right)}{\beta u^{\prime}\left(c_{2, t+1}\right)}=\frac{\left[1-\delta+f_{k}\left(\frac{s_{t-1}}{1+n}\right)\left(1+\varphi_{t+1}^{k}\right)\right]}{\left(1+\varphi_{t+1}^{\lambda}\right)} .
$$

To simplify, assume that the depreciation rate $\delta=1$ :

$$
\frac{u^{\prime}\left(c_{1, t}\right)}{\beta u^{\prime}\left(c_{2, t+1}\right)}=f_{k}\left(\frac{s_{t-1}}{1+n}\right) \frac{\left(1+\varphi_{t+1}^{k}\right)}{\left(1+\varphi_{t+1}^{\lambda}\right)} .
$$

In this case, it is clear that the relative strength of each wedge determines the magnitude of the wedge (larger or smaller than 1). The wedge $\varphi^{k}$ is determined by the income distribution in the constraints in the economy, whereas $\varphi^{\lambda}$ is also determined by the relative importance of the young cohorts versus the older ones. 


\section{Implementation by Means of Optimal Wedges}

The implementation of the constrained problem requires wedges and transfers within a given cohort. The optimization problem of the representative newborn is given by

$$
\max u\left(c_{1, t}\right)+\beta u\left(c_{2, t+1}\right)
$$

subject to

$$
c_{1, t}+s_{t}=w_{t} l_{t}
$$

and

$$
c_{2, t+1}=\frac{1-\delta+r_{t+1}\left(1+\varphi_{t+1}^{k}\right)}{1+\varphi_{t+1}^{\lambda}} s_{t}+T_{t+1} .
$$

This formulation does not allow for intergenerational redistribution-all resources are transferred within the same cohort. The optimality condition of the consumer problem implies

$$
\frac{u^{\prime}\left(w_{t} l_{t}-s_{t}\right)}{\beta u^{\prime}\left(\left[\frac{1-\delta+r_{t+1}\left(1+\varphi_{t+1}^{k}\right)}{1+\varphi_{t+1}^{\prime}}\right] s_{t}+T_{t+1}\right)}=\frac{1-\delta+r_{t+1}\left(1+\varphi_{t+1}^{k}\right)}{1+\varphi_{t+1}^{\lambda}} .
$$

This formulation is silent about the tax instrument used to implement these wedges. Several instruments (e.g., inflation or capital taxation) can manipulate the relative rate of return of savings. To illustrate the importance of these wedges, we compute some numerical examples that show findings comparable to those of Bullard and Waller (2004).

\section{MONEY AND CAPITAL}

\section{Pricing an Additional Asset}

Since the optimal intergenerational redistribution determines the equilibrium interest rate, we can also think about these parameters as the determining factors in an economy in which capital and money are perfect substitutes. Thus, the equilibrium return on capital pins down the real rate of return on money and thus the inflation rate. In this economy, one can imagine the per capita money growth rate evolving according to $M_{t+1}(1+n)=\left(1+z_{t}\right) M_{t}$. The real rate of return on money is given by $\left(1+\pi_{t}\right)^{-1}$, where $\pi_{t}$ is the net inflation rate in period $t$. Arbitrage then implies that

$$
f_{k}\left(k_{t}\right)=\frac{1}{1+\pi_{t}}=\frac{1+n}{1+z_{t}}
$$

We do not explicitly model the reason agents hold money in this economy. Rather, we think of this exercise as being able to price an asset that is held in zero net supply. This is similar in spirit to Woodford's (2003) "cashless" economy.

Since the rate of return from capital is the same as money, it is possible to write the consumer's budget constraint as 


$$
c_{2, t+1}=\frac{v_{t+1}}{v_{t}} s_{t+1},
$$

where $v_{t+1} / v_{t}=(1+n) /\left(1+z_{t}\right)=1 /\left(1+\tau_{t}\right)$. The term $v_{t+1} / v_{t}$ is the rate of return from holding money, $n$ is the population growth rate, and $z$ is the rate of money growth. These terms should be equal to the optimal wedge $\tau$. Replacing the expression in the budget constraint implies

$$
\left(1+\tau_{t}\right) c_{2, t+1}=s_{t+1}
$$

The optimal wedge takes a different form, but it affects the relative price of consumption. Arbitrage between money and capital ensures that the economy implements the constrained efficient stock of capital. This model ties the constrained efficient level of capital to the implied inflation rate that would have to prevail to equate rates of return on assets.

It is important to emphasize that the optimal rate of inflation is derived from the primitives of redistribution and not the other way around. If we impose the arbitrage condition into the planner's problem, the optimal capital stock would be determined by $z$. In this case, the effects of savings in the stock of capital become irrelevant because the exogenous arbitrage condition would determine the efficient stock of capital, and the level would not necessarily be consistent with the intergenerational discount factor $\lambda$.

\section{Numerical Example}

Functional Forms and Optimality. The numerical example compares the solution of the unconstrained efficient problem with the constrained one. The objective is to illustrate the differences in capital stocks achieved by these economies and the implied redistributional policies. We consider individual preferences of the form

$$
U\left(c_{1, t}, c_{2, t+1}\right)=\frac{c_{1, t}^{1-\sigma}}{1-\sigma}+\beta \frac{c_{2, t+1}^{1-\sigma}}{1-\sigma},
$$

where $\sigma$ represents the curvature of the utility function. The production technology is CobbDouglas $f(k)=A k^{\alpha}$. The term $A$ represents the productivity level and $\alpha$ the curvature parameter. For this functional form, the unconstrained efficient problem has a closed-form solution. The optimal level of capital depends on the intergenerational parameter $\lambda$. A larger weight on future generations implies a higher capital stock and higher wages for the young cohort:

$$
k^{*}(\lambda)=\left[\frac{\alpha A \lambda}{1+n-\lambda(1-\delta)}\right]^{\frac{1}{1-\alpha}} .
$$

Given the level of capital, the distribution of consumption depends on $\lambda$ :

$$
c_{2}=\left[\frac{\beta(1+n)}{\lambda}\right]^{\frac{1}{\sigma}} c_{1},
$$

whereby higher values of $\lambda$ imply lower relative consumption for the current old cohort. Finally, the level of consumption for each cohort is determined by net output: 


\section{Figure 3}

\section{Capital Stock}

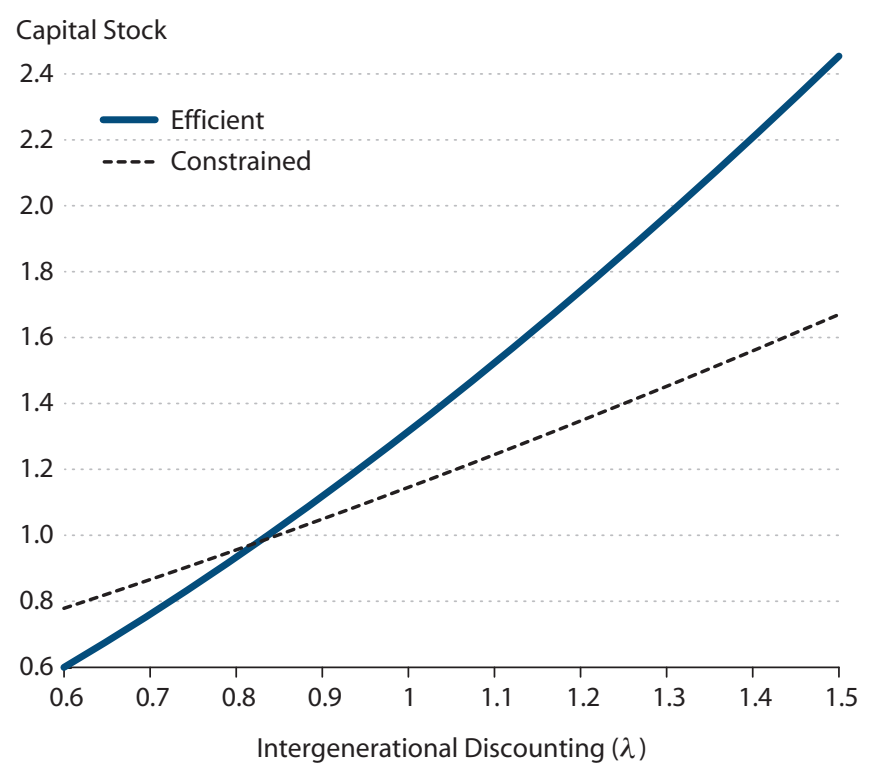

$$
c_{1}+\frac{c_{2}}{1+n}=y(\lambda)=A k^{*}(\lambda)^{\alpha}-(\delta+n) k^{*}(\lambda) .
$$

The constrained efficient problem does not have closed-form solutions and requires solving a nonlinear equation for the capital stock, $k$, given by

$$
\frac{\left[f_{l}(k) l-(1+n) k\right]^{-\sigma}}{\beta\left\{\left[1-\delta+f_{k}(k)\right](1+n) k\right\}^{-\sigma}}=\frac{1-\delta+\alpha^{2} A k^{\alpha-1}}{1+(1-\alpha) \alpha A k^{\alpha-1}} .
$$

The parameters used in the steady-state simulations are chosen to be fairly consistent with standard macroeconomic aggregates, but the selection of the two-period economy is mainly for illustrative purposes. The table below summarizes the parameter values used in the numerical experiments.

\begin{tabular}{cl} 
Parameter & Value \\
\hline$\alpha$ & 0.35 \\
$A$ & 10 \\
$I=\delta$ & 1 \\
$\sigma$ & 2 \\
$n$ & $0.996^{30}$ \\
$\beta$ & $0.979^{30}$
\end{tabular}




\section{Figure 4}

\section{Consumption Share: Young Cohort}

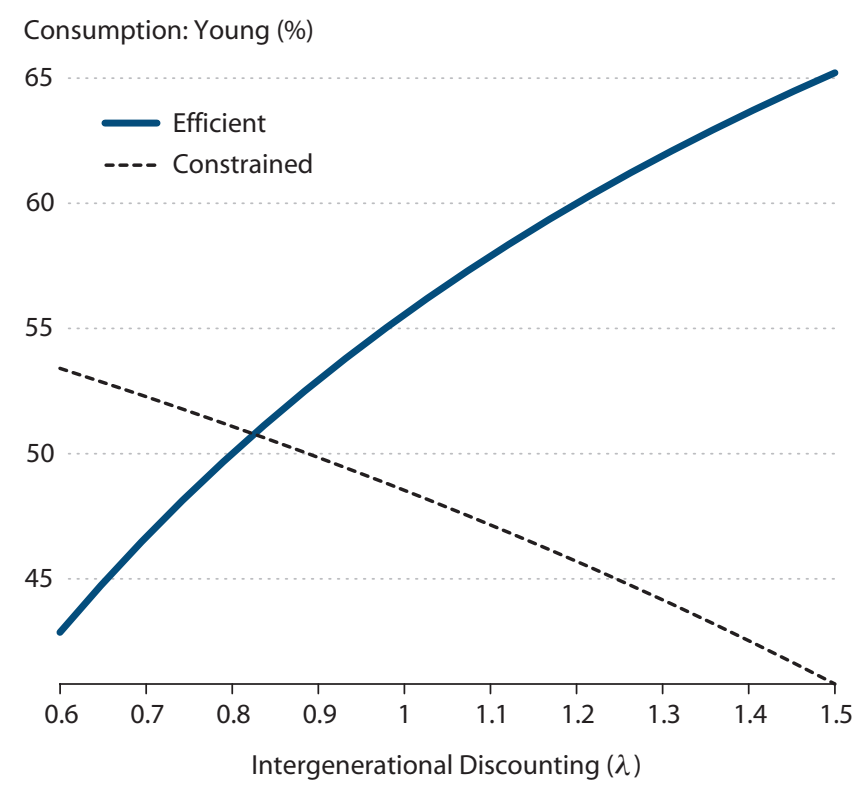

Steady-State Comparisons. Given this parameterization, Figure 3 summarizes the optimal capital stock for both constrained and unconstrained economies as a function of the parameter $\lambda$. The capital stock is plotted as deviations from the efficient level. There exists a parameter $\lambda$ for which the constrained efficient solution is optimal.

Higher values of $\lambda$ imply that the constrained solution has an insufficient level of capital compared with the efficient solution. The reason is that as more weight is placed on the future young, the current cohort must save more and reduce its consumption. This increases the endogenous component $\gamma_{2}$ and prevents the economy from achieving the efficient solution. The model predicts the opposite effect for low values of $\lambda$. The economy is not dynamically inefficient in the classical sense, $r<n+\delta$, but the market solution can have too much or too little capital relative to the efficient (dynamically efficient) level.

The redistributional constraints have important implications for the cross section of consumption. Figure 4 compares the share of consumption of the young cohorts as a fraction of total consumption.

In the presence of lump-sum transfers, a larger value of $\lambda$ implies a greater share of consumption for the young. However, in the constrained efficient steady state, the relative weight of old cohorts, $\gamma_{2, t}$, increases. As a result, the share of consumption for young cohorts decreases because the only way to achieve a higher capital stock is to decrease the consumption of the young. The absence of intergenerational transfers prevents increasing both consumption and capital simultaneously. Figure 5 shows the implied wedge consistent with the high savings rate.

In the market economy, young cohorts can be induced to save more and reduce the current consumption only when the return from capital is higher than the marginal product of capital. 


\section{Figure 5}

\section{Optimal Wedge}

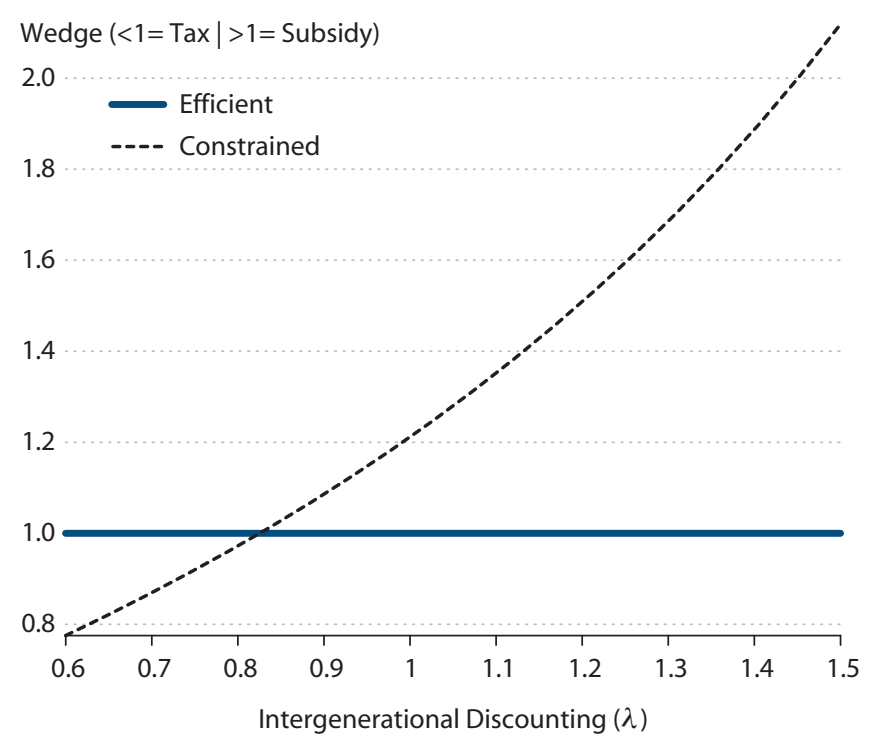

When the economy has too much capital relative to the efficient level, the optimal strategy is to reduce the return on savings of the old cohorts.

The notion of inflation or deflation should be viewed relative to the efficient magnitude, $\pi^{*}$. It is possible to construct examples where the constrained efficient inflation rate is negative, $\pi<0$, or positive, $\pi>0$. The role of redistributional policy implies that $\pi\left(\lambda<\lambda^{*}\right)<\pi\left(\lambda^{*}\right)<$ $\pi\left(\lambda>\lambda^{*}\right)$ for different ranges of $\lambda$. When population growth is positive, the equilibrium interest rate is always positive, $r=n$, and the redistribution is accomplished by changing the optimal rate of deflation, $z^{*}<0$. When the size of the population shrinks (i.e., after a baby boom), then $r=n<1$ and the efficient rate of inflation can be positive or negative depending on the distributional factor $\lambda$. Figure 6 summarizes the annualized inflation rate implied by the model.

In this economy, the monetary equilibrium implies $r<1$, and as a result the crossing line between efficient and constrained solutions implies $\pi>0$. The relevant result is not the level of inflation but the relative preference for different individuals in the population. This economy illustrates the basic trade-off between the young and old cohorts: The young cohorts prefer higher inflation (or less deflation) and the old cohorts prefer the opposite. This trade-off is clear in the efficient economy and the constrained efficient economy, but the relative difference in both economies is due to the absence of intergenerational transfers. When the old cohorts are relatively more important, the optimal inflation rate is determined by the size of the capital stock. Ideally, it would be optimal to have more capital, but the young are the ones who need to give up consumption to achieve the needed level of savings. Since this would violate their budget constraint, the resulting policy implies deflation (redistribution toward the old), but the magnitude is not as large as in the efficient case because of the binding role of the redistributional constraints. 


\section{Figure 6}

\section{Annualized Inflation $(n<0)$}

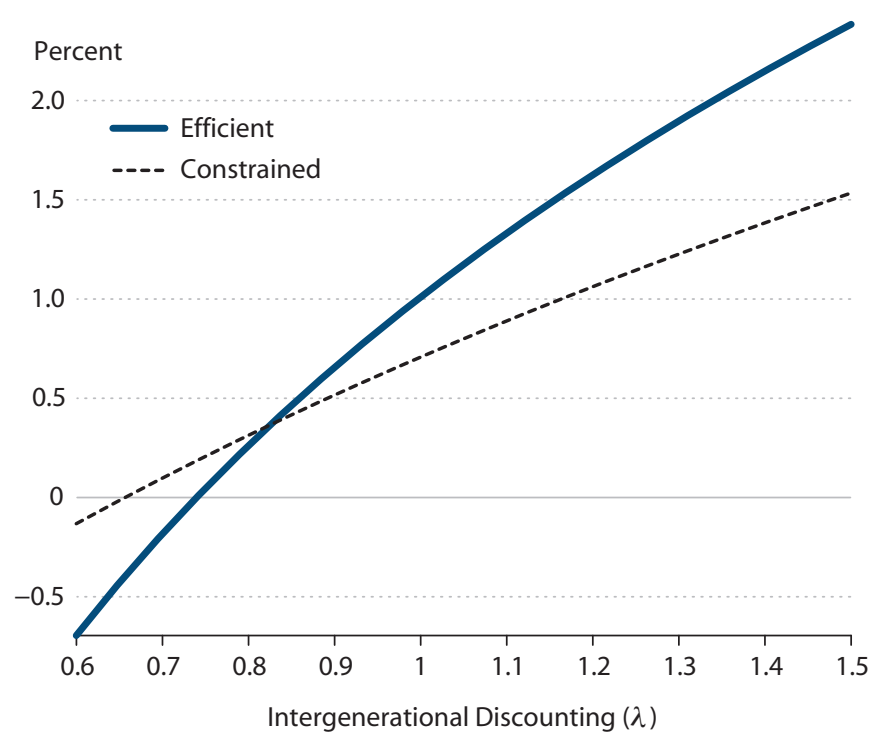

Figure 7

Annualized Inflation $(n=0)$

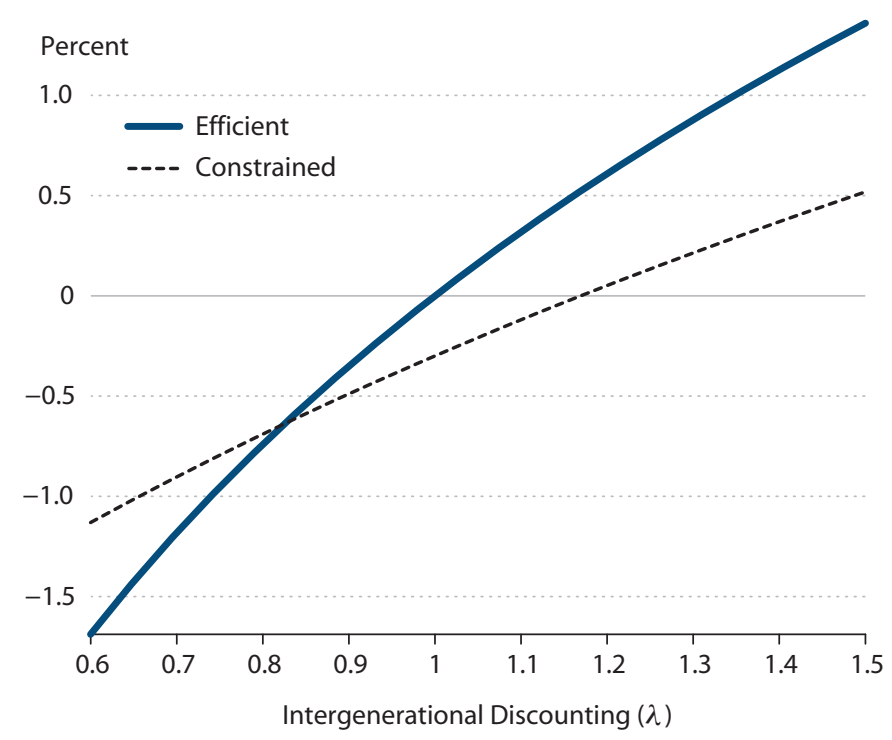




\section{Figure 8}

\section{Taxes and Transfers}

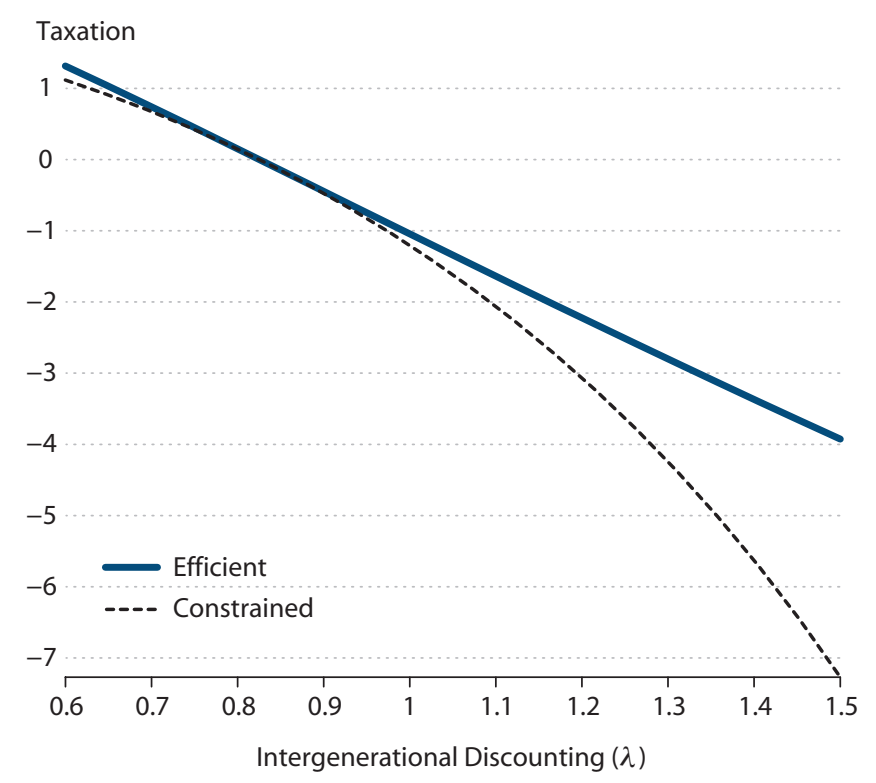

The level of inflation depends on the growth rate of the population. With stationary population growth, $n=0$, the interest rate is always above 1 percent and the optimal inflation is always negative (Figure 7).

The model also predicts that the young cohorts prefer a lower negative growth of money, whereas the old cohorts prefer a higher rate of deflation. The quantitative magnitudes depend on the parameterization, but the qualitative tension between young and old cohorts is consistent with the political economy equilibrium of Bullard and Waller (2004).

The revenue/loss raised by the optimal wedge is rebated to the old cohort. Figure 8 compares the tax/transfers paid by the old cohort for both economies.

For a given value of $\lambda$, the efficient economy always has more redistribution than the constrained efficient one. When both economies achieve similar capital stock levels, the role of redistribution becomes less important and the consumption shares of each cohort are nearly the same.

\section{TRANSITIONAL DYNAMICS}

The steady-state calculations are useful only to illustrate the static trade-off. By definition, the young and the old cohorts must face the same prices. The current young cohort might earn a high wage today but will be an old cohort tomorrow, earning a low rate of return. In the transition path, the stock of capital changes; therefore, the prices faced by a given generation at time $t$ will differ from those faced by the next generation at $t+1$. 
The intuition is clear from the Euler equation of the constrained efficient problem:

$$
c_{1, t}^{-\sigma}=\frac{\lambda_{t+1}}{\lambda_{t}} c_{1, t+1}^{-\sigma}\left[(1-\alpha) \alpha A k_{t+1}^{\alpha-1}\right]+\beta c_{2, t+1}^{-\sigma}\left[1-\delta+\alpha^{2} A k_{t+1}^{\alpha-1}\right] .
$$

An increase in savings reduces the consumption of the current young, $c_{1, t}$; increases the compensation of the future young cohort, $c_{1, t+1}$, through wages; and decreases the return from savings of the young cohort next period, $c_{2, t+1}$. Because the current young and the future old are the same individuals, the relative weight $\lambda_{t}$ cancels.

The Euler equation of the efficient solution is very different but has the same economic interpretation. The intergenerational redistribution is done directly; as a result, market prices are not distorted:

$$
c_{1, t}^{-\sigma}=\frac{\lambda_{t+1}}{\lambda_{t}} c_{1, t+1}^{-\sigma}\left[1-\delta+\alpha A k_{t+1}^{\alpha-1}\right] .
$$

It is clear from the expression that an increase of the relative weight of future cohorts, $\lambda_{t+1} / \lambda_{t}>1$, will reduce consumption of the current generation (increase in savings) relative to future generations. The increased savings are sustained by intergenerational transfers.

A simple way to capture the effects of demographic changes is to adjust the relative importance of a given cohort in the social welfare function. When current generations become relatively more important than future generations, the capital stock will increase. A higher capital stock reduces the return on savings and increases workers' compensation.

In the experiment we adjust the initial discount rate $\lambda$ so both economies start with the same stock of capital. Therefore, the constrained economy is efficient with an optimal wedge equal to zero. The implied inflation is determined by the arbitrage condition between capital and money. We consider two different sequences of intergenerational weights $\left\{\lambda_{t}\right\}$. In case 1 , the relative importance of young cohorts increases during a small number of periods. In case 2 , the high $\lambda$ is maintained during a larger number of periods. The difference sequences illustrated in Figure 9 summarize the behavior of the model in these two cases.

Our desired interpretation is that the young cohorts become temporarily more important in the determination of the optimal policy. The change is transitory and eventually reverts to the initial level. The change in the social discount rate has implications for savings and consumption. The initial steady state is no longer optimal at the new discount rates $\left\{\lambda_{t}\right\}$. The implicit baby boom generates a change in policy. To incentivize savings the rate of return on money must decrease (this is the standard Tobin effect in this model). The implied policy generates a hump-shaped response from inflation.

Figure 10 summarizes the evolution of annualized inflation along the transition path. Both economies increase the inflation rate relative to the initial steady state. The persistence of inflation is entirely determined by $\lambda . \underline{5}$ Along the transition path the rise in savings increases the compensation of working generations and reduces the return from savings for the existing old cohort. In the efficient economy, the optimal inflation rate can be sustained by intergenerational policy. The constrained economy has more limitations regarding the transfer of resources across generations. Market prices are the only mechanism young individuals can use to save the right amount. As a result, the constrained inflation rate is lower during the boom but higher during 


\section{Figure 9}

\section{Intergenerational Discount Rate}
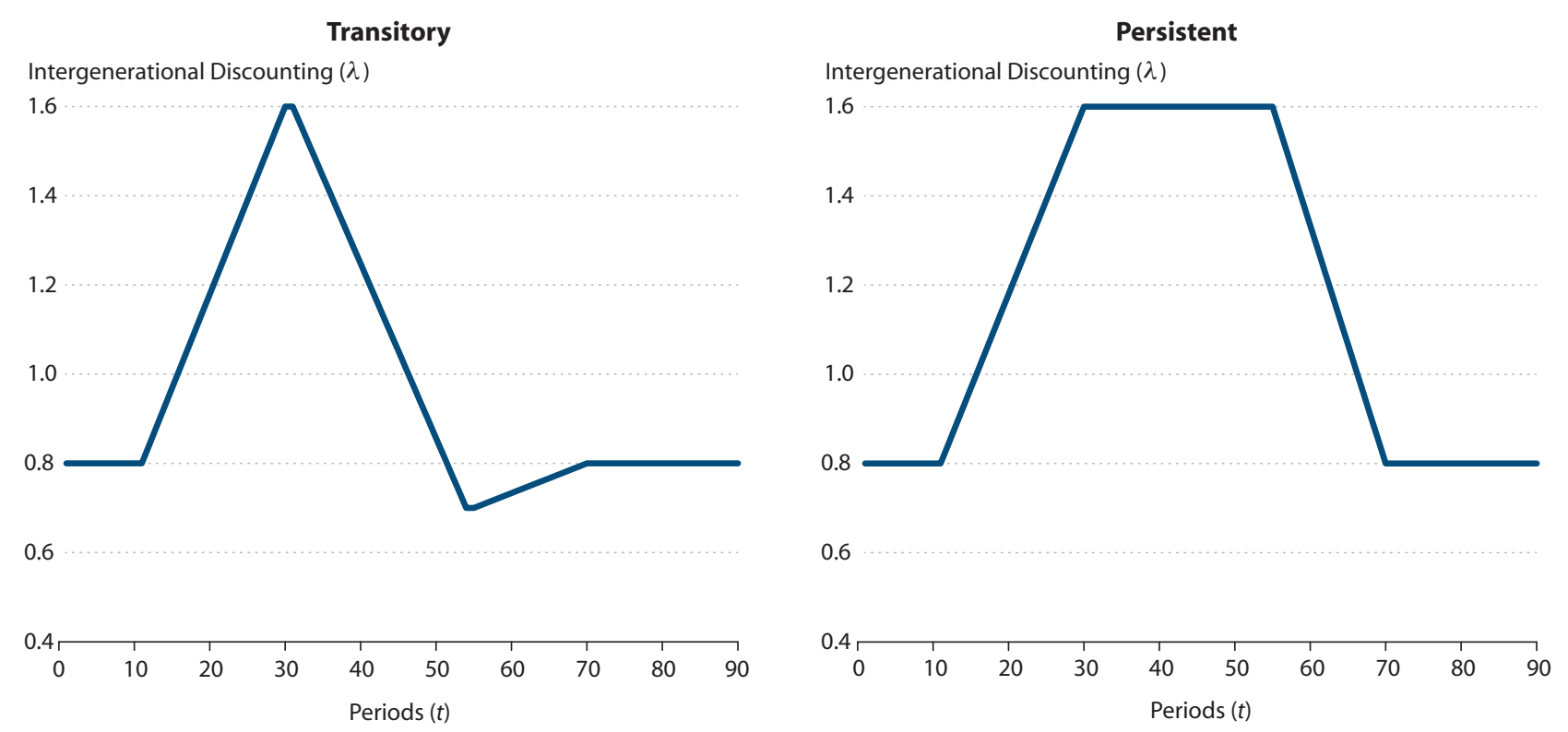

\section{Figure 10}

\section{Annualized Inflation}
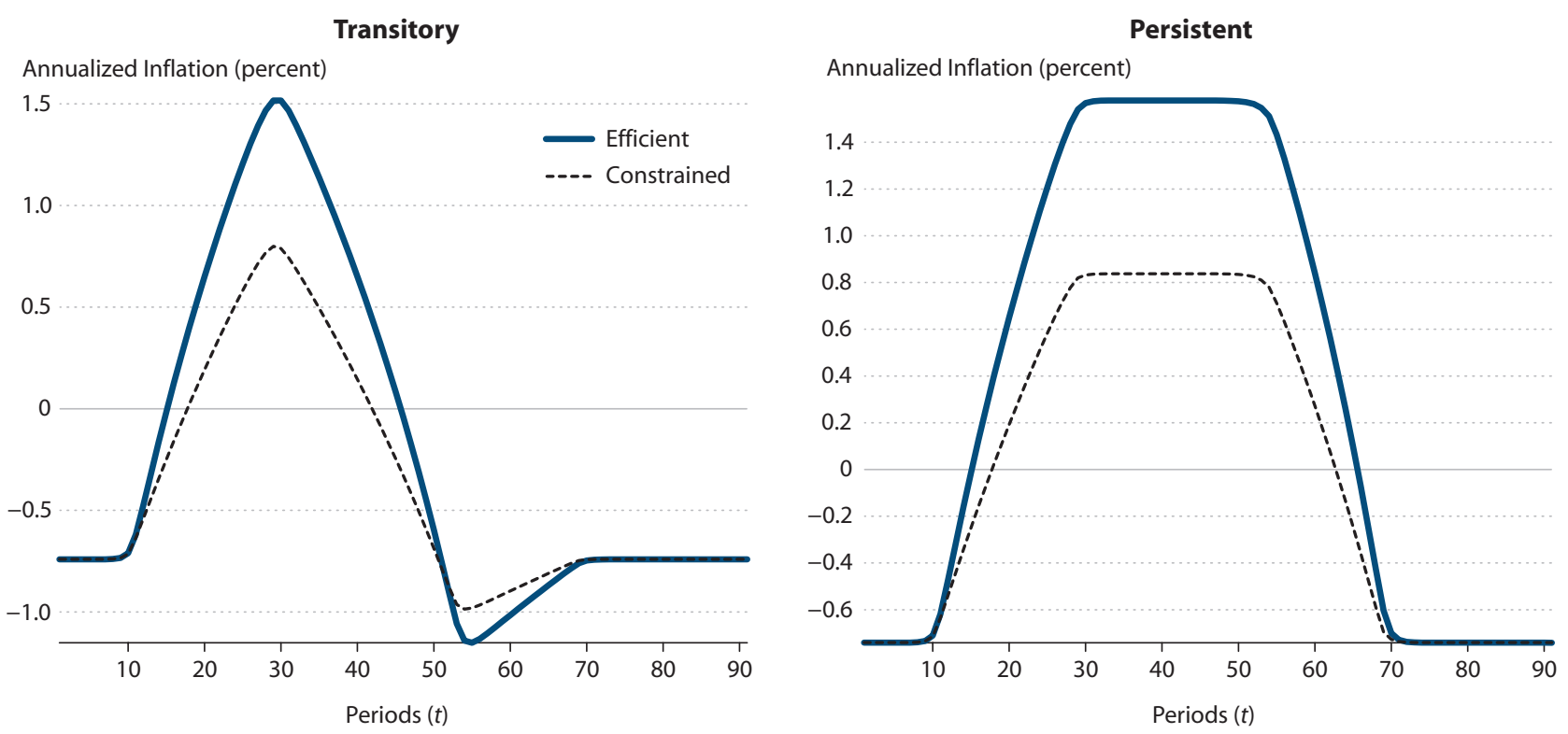


\section{Figure 11}

\section{Interest Rates}
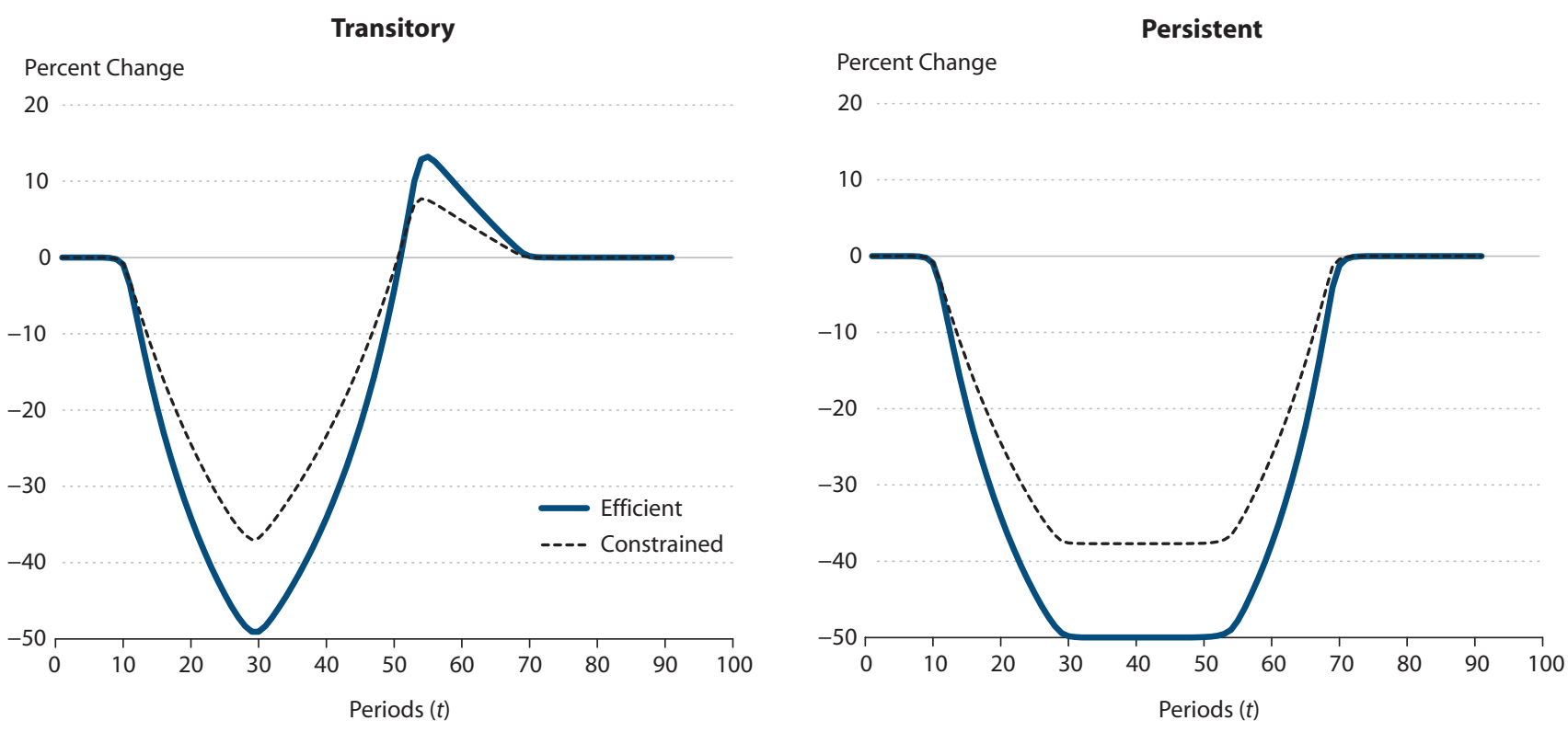

the bust. The underlying income distribution between wage earners and the asset-holding generation places bounds on the optimal policy.

The increase in the savings rate reduces the return from capital and increases the workers' compensation. Figure 11 summarizes the evolution of real interest rates as a percentage change of the initial steady state. The path of interest rates is entirely driven by the sequence of $\left\{\lambda_{t}\right\}$. In the constrained efficient economy, the optimal inflation rate is not sufficiently high to encourage a higher savings rate. As a result, the interest rate does not fall as much during the boom and workers' compensation cannot increase to the efficient levels.

\section{CONCLUSION}

We study the interaction among population demographics, the desire for redistribution of resources in the economy, and the optimal inflation rate in a deterministic economy with capital. In the economy we study, changes in the population structure are interpreted as the ability of a particular cohort to influence redistributive policy. The intergenerational redistributional tension is intrinsic in life cycle models. Young cohorts have few assets and wages are the main source of income. Old generations work less and prefer a high rate of return from their savings. When the government has access to lump-sum taxes and transfers, redistributive policy need not resort to distortionary measures (such as capital taxes or inflation). When lump-sum transfers are not possible but the planner is allowed to use inflation or deflation to achieve as much of the redistribution as possible, there exists a competitive equilibrium with a constrained efficient redistributive policy. The equilibrium requires optimal distortions on relative prices that 


\section{Bullard, Garriga, Waller}

are necessary to achieve the constrained efficient allocation. When the old have more influence over this redistributive policy, the economy has a lower steady-state level of capital, a higher steady-state real rate of return, and a lower or negative rate of inflation. By contrast, when the young have more influence, the economy has more capital than the efficient level, wages are relatively high, and the market solution requires a low rate of return from money holdings - that is, a relatively high inflation rate.

When demographics are changing, the constrained efficient solution requires an entire transition path that alters capital stocks, inflation, real wages, consumption, and other key macroeconomic variables. In particular, a baby boom can generate temporarily higher inflation, and aging population dynamics will put downward pressure on inflation or even lead to deflation. This scenario seems broadly consistent with the rough evidence presented in Figures 1 and 2.

In this article, we have allowed a planning problem to substitute for the political processes used by society to make decisions concerning redistributional policy. More concrete examples of political processes, including a policy committee that uses Nash bargaining to reach a social decision, are studied in Bullard and Waller (2004). By contrast, in this article the planner optimally chooses inflation or deflation to achieve as much of the desirable redistribution as possible given that the choice of inflation or deflation provides only a partial substitute for a fully operational lump-sum tax and transfer scheme. The society could use other types of distortionary taxes to achieve similar goals, so we interpret our findings as providing an assessment of the marginal contribution of inflation or deflation in this process, taking the existing distortionary tax system as fixed and immutable.

At face value, the results in this article contribute to the debate concerning the observation of mild deflation in Japan with its aging population structure. The results suggest that the aging population may be optimally associated with lower inflation as part of the constrained efficient equilibrium. We think it will be interesting to study this hypothesis further in models that can more realistically quantify these effects. For example, the presumption that the young prefer high wages and the old prefer high returns on wealth could be tested using cross-country data. The model needs further development in terms of the role of monetary policy because monetary policy plays no role in determining inflation rates in an economy where capital and money have the same rate of return.

\section{NOTES}

1 "Closely related" would apply to cases where the return on capital and the return on money were not exactly equal but differed only by a constant, so that the two rates still moved in tandem.

$\underline{2}$ The moving average inflation rate in Japan during the mid-1970s is truncated at 10 percent to allow a better view of the two data series.

3 Bullard and Waller did not focus directly on demographic effects.

4 Judd (1985) considers a redistributional trade-off between wage earners and capital earners. In that economy, the optimal redistribution is independent of the relative weight of each group in the social welfare function. In terms of monetary policy, in that economy the central bank should set the nominal interest rate to zero.

$\underline{5}$ The nature of the two-period problem requires an assumption of a high depreciation rate; we used $\delta=1$. Given that all capital depreciates from one period to the next, the dynamics in terms of quantities per period are very fast. We believe the same dynamics would hold in more elaborate general equilibrium life cycle settings, but the computational cost would be higher. 
Bullard, Garriga, Waller

\section{REFERENCES}

Bullard, James and Waller, Christopher J. "Central Bank Design in General Equilibrium." Journal of Money, Credit, and Banking, February 2004, 36(1), pp. 95-113.

Dávila, Julio. "The Taxation of Capital Returns in Overlapping Generations Models." Journal of Macroeconomics, June 2012, 34(2), pp. 441-53.

Dávila, Julio; Hong, Jay H.; Krusell, Per and Ríos-Rull, Jóse-Victor. “Constrained Efficiency in the Neoclassical Growth Model with Uninsurable Idiosyncratic Shocks." Econometrica (forthcoming).

Garriga, Carlos. "Optimal Fiscal Policy in Overlapping Generations Models." CREB Working Paper No. 0105, Center for Research in Welfare Economics, January 2001.

Garriga, Carlos and Sánchez-Losada, Fernando. “Estate Taxation with Warm-Glow Altruism." Portuguese Economic Journal, August 2009, 8(2), pp. 99-118.

Judd, Kenneth L. “Redistributive Taxation in a Simple Perfect Foresight Model." Journal of Public Economics, October 1985, 28(1), pp. 59-83.

Woodford, Michael. Interest and Prices: Foundations of a Theory of Monetary Policy. Princeton, NJ: Princeton University Press, 2003. 


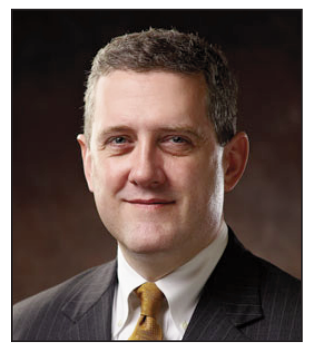

\section{James Bullard}

President and CEO, Federal Reserve Bank of St. Louis

http://research.stlouisfed.org/econ/bullard/

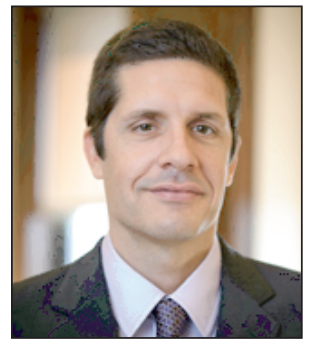

\section{Carlos Garriga}

Research officer and economist, Federal Reserve Bank of St. Louis

http://research.stlouisfed.org/econ/garriga/

\section{Research Focus}

Carlos Garriga's recent research has focused on house price movements, mortgage finance, and the macroeconomic implications of housing. Past research has analyzed the issues of optimal fiscal policy, the design of social security reforms, and the financing of education.

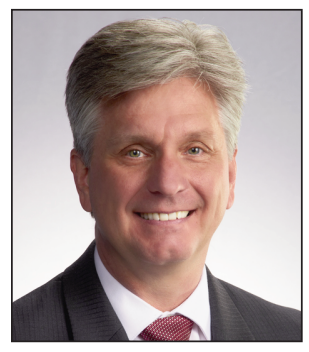

\section{Christopher J. Waller}

Senior vice president and director of research, Federal Reserve Bank of St. Louis

http://research.stlouisfed.org/econ/waller/

\section{Research Focus}

Chris Waller's areas of interest are monetary theory, political economy, and macroeconomic theory. 